\title{
Anti-parasitic effect of novel amidines against Trypanosoma cruzi: phenotypic and in silico absorption, distribution, metabolism, excretion and toxicity analysis
}

\author{
ALINE SILVA DA GAMA NEFERTITI ${ }^{1}$, MARCOS MEUSER BATISTA ${ }^{1}$, \\ PATRÍCIA BERNARDINO DA SILVA ${ }^{1}$, EDUARDO CAIO TORRES-SANTOS ${ }^{2}$, \\ EDEZIO F. CUNHA-JÚNIOR ${ }^{2}$, JULIUS GREEN ${ }^{3}$, ARVIND KUMAR $^{3}$, \\ ABDELBASSET A. FARAHAT ${ }^{3,4}$, DAVID WILSON BOYKIN ${ }^{3}$ \\ and MARIA DE NAZARE CORREIA SOEIRO ${ }^{1 *}$ \\ ${ }^{1}$ Laboratório de Biologia Celular, Instituto Oswaldo Cruz, Fundação Oswaldo Cruz, Rio de Faneiro, Rio de Faneiro, \\ Brazil \\ ${ }^{2}$ Laboratório de Bioquímica de Tripanosomatideos, Instituto Oswaldo Cruz, Fundação Oswaldo Cruz, Rio de Faneiro, \\ Rio de faneiro, Brazil \\ ${ }^{3}$ Department of Chemistry, Georgia State University, Atlanta, Georgia, USA \\ ${ }^{4}$ Department of Pharmaceutical Organic Chemistry, Faculty of Pharmacy, Mansoura University, Mansoura 35516, Egypt
}

(Received 3 Fanuary 2017; revised 14 March 2017; accepted 16 March 2017)

SUMMARY

New more selective and potent drugs are urgently need to treat Chagas disease (CD). Among the many synthetic compounds evaluated against Trypanosoma cruzi, aromatic amidines (AAs) and especially arylimidamides (AIAs) have potent activity against this parasite. Presently, the effect of four mono-amidines (DB2228, DB2229, DB2292 and DB2294), four diamidines (DB2232, DB2235, DB2251 and DB2253) and one AIA (DB2255) was screened in vitro against different forms (bloodstream trypomastigotes - BT and intracellular forms) and strains from discrete typing unit (DTU) I and VI of T. cruzi and their cytotoxic profile on mammalian host cells. Except for DB2253, all molecules were as active as benznidazole $(\mathrm{Bz})$, resulting in $50 \%$ of reduction in the number of alive $\mathrm{BT}$, with $\mathrm{EC}_{50}$ ranging from $2 \cdot 7$ to $10 \cdot 1 \mu \mathrm{M}$ after $24 \mathrm{~h}$ of incubation. DB2255 was also the most potent against amastigotes (Tulahuen strain) showing similar activity to that of $\mathrm{Bz}(3 \mu \mathrm{M})$. In silico absorption, distribution, metabolism, excretion and toxicity analysis demonstrated probability of human intestinal adsorption, while mutagenicity and inhibition of hERG1 were not predicted, besides giving acceptable predicted volumes of distribution. Our findings contribute for better knowledge regarding the biological effect of this class of aromatic molecules against T. cruzi aiming to identify novel promising agent for CD therapy.

Key words: aromatic amidines, Chagas disease, experimental chemotherapy, toxicity, selectivity, in silico ADMET analysis.

\section{INTRODUCTION}

Over 100 years ago, Carlos Chagas, a Brazilian researcher discovered a new disease, American trypanosimiasis or Chagas disease (CD) caused by a flagellated protozoan Trypanosoma cruzi. CD is endemic to 21 countries of Latin American, affecting more than 6 million individuals (WHO, 2016).

$\mathrm{CD}$ is currently emerging in non-endemic areas, such as North America, Europe and Oceania, mostly associated with the migration of infected carriers (Albajar-Viñas and Dias, 2014). CD presents in two stages: an acute and a later chronic phase, which after years or decades about $30-40 \%$ of patients progress to symptomatic forms, causing heart disease and/or digestive and neurological disorders (Teixeira et al. 2006; Marin-Neto et al. 2008; Coura and Dias, 2015). The two drugs currently

* Corresponding author: Laboratório de Biologia Celular, Instituto Oswaldo Cruz, Fundação Oswaldo Cruz, Av. Brasil, 4365 Manguinhos, Rio de Janeiro, Brazil. E-mail: soeiro@ioc.fiocruz.br available for clinical treatment are the nitroderivates, nifurtimox (Nif) and benznidazole $(\mathrm{Bz})$, were introduced about four decades ago into clinical use and up to now remain the only treatment options (Patterson and Wyllie, 2014). The major limitations of these compounds include the need for long-time administration and their considerable side-effects that in some cases leads to the discontinuation of treatment, therapeutic failure at the later chronic phase and exhibition of limited effectiveness against naturally resistant strains (Wilkinson et al. 2008). A novel candidate for CD therapy should present as drug characteristics: (i) efficacy upon the two phases of the disease, especially the later chronic stage; (ii) potency on different parasite discrete typing units (DTUs; I, II, V and VI) and forms relevant for human infection (trypomastigotes and amastigotes); (iii) low toxicity and absence of genotoxicity, mutagenicity and cardiotoxicity; (iv) be orally administrated; (v) with good stability (3-5 years in climatic zone) with (vi) low costs (Chatelain and Konar, 2015; DNDi, 2016). 
A recent clinical trial, which included a 5-year follow-up, seeking the benefits of the trypanocidal therapy using $\mathrm{Bz}$ in patients with established Chagas' cardiomyopathy showed that although there was a significant reduction in total parasite load, this drug was not able to impair cardiac clinical deterioration (Morillo et al. 2015). These findings corroborate the need to find alternative therapies for CD. Aromatic amidines (AA) are dicationic molecules with many of them such as pentamidine $(\mathrm{Pt})$ presenting DNA minor groove-binding characteristics (Soeiro et al. 2013). The anti-parasitic action of Pt has been known since 1937 (King et al. 1937) and in the ensuing years many analogues and derivatives have been synthetized and screened against parasitic organisms. Several of these molecules have demonstrated a wide spectrum of activity against human and veterinary pathogens such as leishmaniasis, human African trypanosomes and T. cruzi (De Souza et al. 2004; Soeiro et al. 2008, 2013; De Araújo et al. 2014). Among novel amidine molecules, the arylimidamides (AIAs) have shown very promising profiles and potent activity against intracellular parasites like Neospora caninum, Leishmania sp and T. cruzi (Soeiro et al. 2013). The present study investigates the anti- $T$. cruzi activity of additional novel amidines (four mono-amidines, four diamidines and one AIA) through phenotypic studies in vitro by assessing different forms and parasite strains besides determining their toxicity towards different host cell types (as L929 cell lines and primary cultures of cardiac cells) and their absorption, distribution, metabolism, excretion and toxicity (ADMET) properties from in silico predictions.

\section{MATERIAL AND METHODS}

\section{Compounds}

The synthesis of the four studied mono-amidines $(2-$ $(5-(4-)(1$ (quinolin - yl-1-1,2,3-triazol-4-yl) methoxy) phenyl) thiophen-2-yl)-1H-benzo[d]imidazole-6-carboximidamide hydrochloride (DB2228), 2-(5-(4-((1-(2-(naphthalen-1-yl) ethyl) - 1H-1,2,3triazol-4-yl) methoxy) phenyl) thiophen-2-yl)1H-benzo[d]imidazole-6-carboximidamide hydrochloride (DB2229), 2-(5-4-((1-(2-(2-(naphthalene-2yloxy) ethoxy) ethyl)-1H-1,2,3-triazol-4-yl) methoxy) phenyl) thiophen- 2- yl-1H-benzo[d]imidazole - 6 carboximidamide hydrochloride (DB2292) and 2(5-(4-((1- (2-(2-(2-(naphthalene-2-yloxy) ethoxy) ethoxy) ethyl)-1H-1,2,3- triazol - 4-yl) methoxy) phenyl) thiophen-2-yl)-1H-benzo[d]imidazole-6-carboximidamide hydrochloride (DB2294)) has been previously described (Green, 2014). The synthetic route of the four diamidines $\left(2,2^{\prime}-((\right.$ propane1,3-diylbis (oxy)) bis (4,1-phenylene)) bis (1H-benzo [d]imidazole-6-carboximidamide) dihydrochloride
(DB2232), 4,4'-(1-phenyl-1H-pyrrole-2,5-diyl) dibenzimidamide dihydrochloride (DB2235), 2,2'-((1phenyl-1 H-pyrrole-2,5-diyl) bis (4,1-phenylene)) bis (4,5-dihydro- $1 \mathrm{H}$-imidazole) dihydrochloride (DB2251), 2,2'-((1-phenyl-1H-pyrrole-2,5-diyl) bis (4,1-phenylene)) bis $(1,4,5,6$-tetrahydropyrimidine) dihydrochloride (DB2253)) was also conducted using a methodology previously reported (Ismail et al. 2004; Farahat et al. 2011). The synthesis of the bisAIA N, N"-((2-oxoimidazolidine-1,3-diyl) bis (3-isopropoxy-4,1- phenylene)) dipicolinimidamide dihydrochloride (DB2255) was previously reported (Stephens et al. 2001) (Fig. 1). All compounds have been fully characterized by spectral methods (nuclear magnetic resonance $[\mathrm{NMR}]$ and mass spectrometry $[\mathrm{MS}])$ and by satisfactory $\mathrm{C}, \mathrm{H}, \mathrm{N}$ analysis. Bz (2nitroimidazole; Laboratório Farmacêutico do Estado de Pernambuco [LAFEPE], Brazil) was used as reference drug. Stock solutions were prepared in dimethyl sulfoxide (DMSO) with the final concentration of the solvent never exceeding $0 \cdot 6 \%$ DMSO, which is not toxic to the parasite and mammalian cells.

\section{Parasites}

Bloodstream trypomastigote (BT) forms of the $\mathrm{Y}$ strain were obtained from the blood samples of infected albino Swiss mice at the peak of parasitaemia. The purified parasites were resuspended in Dulbecco's modified Eagle medium (DMEM) supplemented with $10 \%$ fetal bovine serum (FBS) as reported previously (Batista et al. 2010). Trypomastigotes of Tulahuen strain expressing the Escherichia coli $\beta$-galactosidase gene (Buckner et al. 1996) were collected from the supernatant of infected cell cultures (L929 culture) as reported (Romanha et al. 2010).

\section{Cell cultures}

For the toxicity assays on mammalian cells, primary cultures of cardiac cells were obtained from mice embryos plated onto coverslips in 96 well plates previously coated with $0.01 \%$ gelatin (Meirelles et al. 1986). L929 cell lineages were obtained as described and maintained in RPMI-1640 medium ( $\mathrm{pH} 7 \cdot 2-7 \cdot 4)$ without phenol red (Gibco BRL) supplemented with $10 \%$ FBS and $2 \mathrm{~mm}$ glutamine (RPMI), as reported previously (Romanha et al. 2010).

\section{Cytotoxicity in vitro tests}

The cardiac cells were incubated for $24 \mathrm{~h}$ at $37^{\circ} \mathrm{C}$ with different concentrations of each compound diluted in RPMI and then, the morphology, cell density and spontaneous contractibility evaluated by light microscopy and their cellular viability determined by the Presto Blue test as reported 

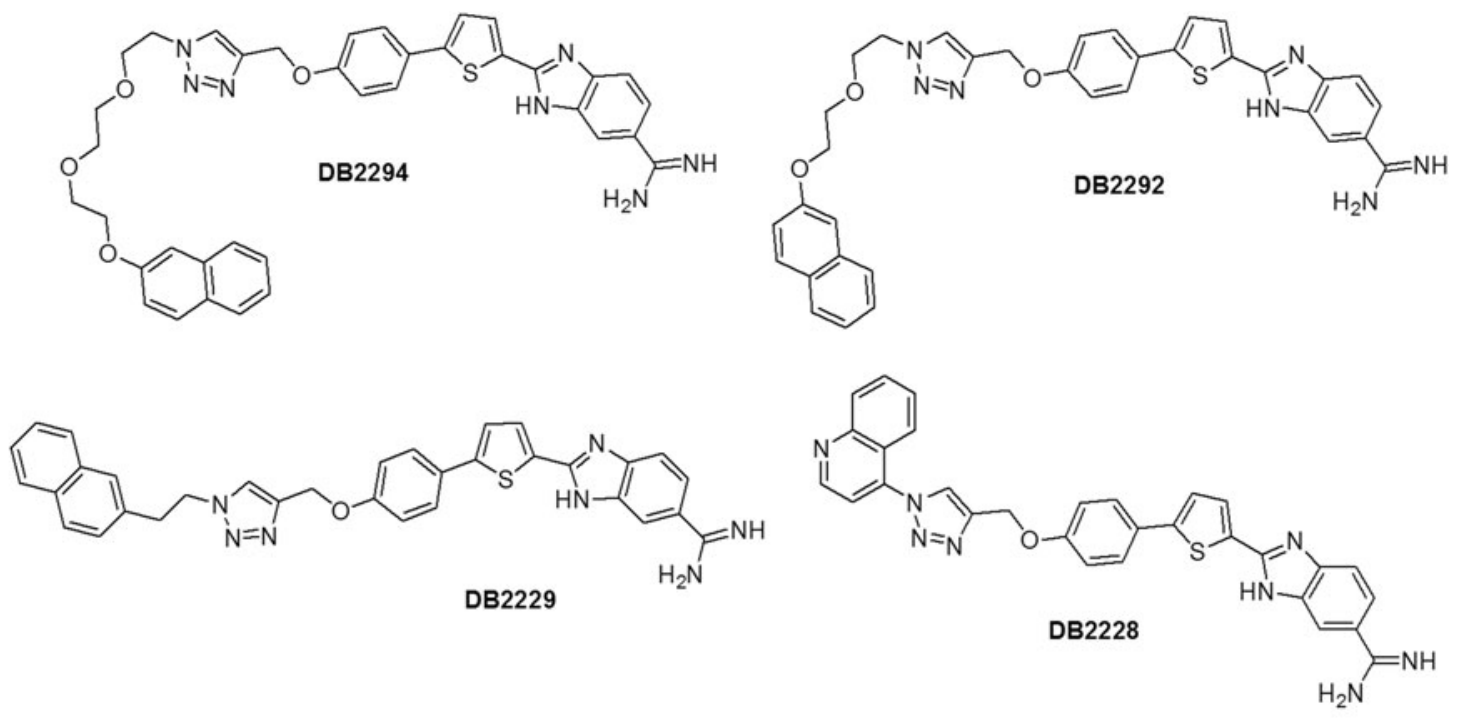<smiles>N=C(N)c1ccc(-c2ccc(-c3ccc(C(=N)N)cc3)n2-c2ccccc2)cc1</smiles>

DB2235<smiles>c1ccc(-n2c(-c3ccc(C4=NCCN4)cc3)ccc2-c2ccc(C3=NCCN3)cc2)cc1</smiles>

DB2251

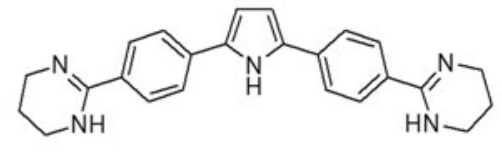

DB2253
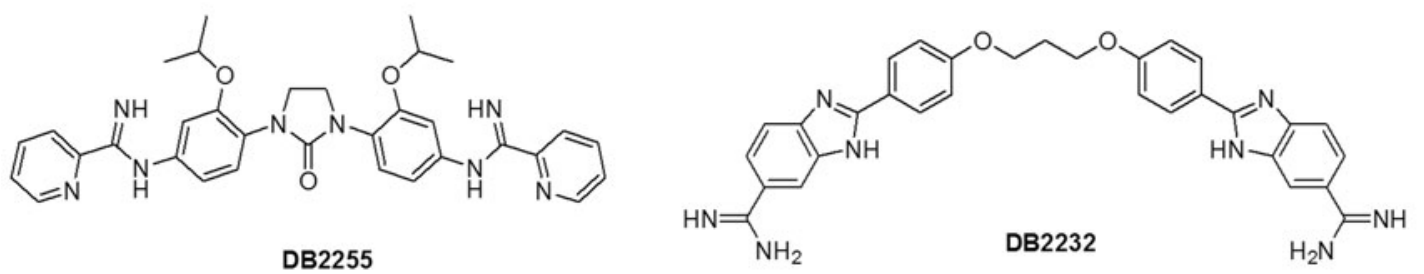

Fig. 1. Chemical structure of the nine selected amidines assayed in this work.

(Timm et al. 2014). L929 cell lineages incubated for 24 and $96 \mathrm{~h}$ at $37^{\circ} \mathrm{C}$, with different concentrations of each compound diluted in RPMI and their cellular viability determined by the AlamarBlue test as reported (Timm et al. 2014). The maximum concentration of each compound was $96 \mu \mathrm{M}$ due to molecule precipitation. The results expressed by following the manufacturer instructions and the value of $\mathrm{CC}_{50}$ that corresponds to the concentration that reduces in $50 \%$ the cellular viability, determined. Selective index (SI) expressed by ratio between the values obtained for $\mathrm{CC}_{50}$ over the host cells and the $\mathrm{EC}_{50}$ obtained over the parasites.

\section{Trypanocidal activity}

Bloodstream trypomastigotes (BT) of the $\mathrm{Y}$ strain (DTU II) (Zingales et al. 2009) $\left(5 \times 10^{6}\right.$ per $\left.\mathrm{mL}\right)$ were incubated for 2 and $24 \mathrm{~h}$ at $37^{\circ} \mathrm{C}$ in RPMI in the presence or not of serial dilution of the compounds (up to $32 \mu \mathrm{M}$ ). After compound incubation, the death parasite rates were determined by light microscopy through the direct quantification of the number of live parasites using a Neubauer chamber, and the $\mathrm{EC}_{50}$ concentration (the compound concentration that reduces in $50 \%$ the number of parasites) was calculated (Timm et al. 2014). For the assay on intracellular forms, culture-derived trypomastigotes of $T$. cruzi (Tulahuen strain expressing $\beta$-galactosidase; DTU VI) (Zingales et al. 2009) used to infect L929 infected-cells cultures using a ratio of 10:1 (parasite: host cell). After $2 \mathrm{~h}$, the cultures rinsed and further incubated for $48 \mathrm{~h}$ for establishment of the infection. Then, the compounds were added (initially using a fixed concentration of $10 \mu \mathrm{M}$ followed by other set of assays using increasing non-toxic concentrations to the mammalian host cell for determination of $\mathrm{EC}_{50}$ values) and the cultures maintained at $37^{\circ} \mathrm{C}$ for $96 \mathrm{~h}$. After addition of $50 \mu \mathrm{L}$ of the substrate [(CPRG - chlorophenol red glycoside) $500 \mathrm{~mm}$ ] in $0.5 \%$ Nonidet $\mathrm{P} 40$ and incubation at $37^{\circ} \mathrm{C}$ for $18 \mathrm{~h}$, the absorbance at $570 \mathrm{~nm}$ was measured, and the results expressed as per cent of parasite growth inhibition (Romanha et al. 2010).

In all assays, at least three experiments $(n \leq 3)$ were done using $\leq 2$ replicates. 
Computational assessment of the drug-like properties of the tested compounds

ADMET properties of the studied amidines evaluated using the pkCSM approach, which uses graphbased signatures to develop predictive ADMET (Pires et al. 2015).

\section{Statistical analysis}

Statistical analysis was performed using Student's $t$ test with significance set at $p \leq 0 \cdot 05$.

\section{Ethics}

All procedures were conducted in accordance with the guidelines established by the FIOCRUZ Committee of Ethics for the Use of Animals (CEUA LW16/14).

\section{RESULTS}

Initially, the biological assays were carried out to evaluate the activity of these molecules upon BT forms (Y strain - DTU II), and their respective toxicity towards cardiac cells. Our findings demonstrate that after a short period of incubation ( $2 \mathrm{~h}$ ), six out of the nine drugs demonstrate trypanosomicidal activity against $\mathrm{BT}$, exhibiting $\mathrm{EC}_{50}$ values lower than $20 \mu \mathrm{M}$, while $\mathrm{Bz}$ was inactive (Table 1). DB2229 and DB2294 displayed an $\mathrm{EC}_{90}$ value $<10 \mu \mathrm{M}$ after only 2 h of compound treatment (Table 1 ) presenting a fast activity towards these forms. After $24 \mathrm{~h}$, seven molecules (DB2228, DB2229, DB2232, DB2235, DB2255, DB2292 and DB2294) were more potent $\left(\mathrm{EC}_{50} \leq 8.3 \mu \mathrm{M}\right)$ than $\mathrm{Bz}(9.6 \mu \mathrm{M})$, being $\mathrm{DB} 2292$ about 3 -fold more active than the reference drug (Table 1). The toxicity profile assessed using cardiac cell cultures to exclude compounds and concentrations that presented cardiotoxic characteristics evaluated by morphological, contractility and density analysis besides through cellular viability approach using a colorimetric methodology (PrestoBlue). Only DB2235 and DB2251 presented detectable toxicity up to the studied concentrations $\left(\mathrm{CC}_{50}=49 \pm 21\right.$ and $62 \pm 23 \mu \mathrm{M}$, respectively) (Table 1).

Next, further assays analysed the activity on intracellular forms of T. cruzi, using the Tulahuen strain transfected with $\beta$-galactosidase, as previous reported (Romanha et al. 2010). The trypanocidal action after $96 \mathrm{~h}$ of incubation using a fixed concentration of 10 $\mu \mathrm{M}$ showed that only the AIA DB2255 displayed a high inhibition of the parasite growth $(88 \%)$, reaching similar activity to that of $\mathrm{Bz}$ (Table 2). Therefore, DB2255 was the only molecule selected for the next screening step, consisting of infection of L929 cells followed by incubation with nontoxic concentrations (up to $32 \mu \mathrm{M}$ ). DB2255 and Bz presented similar potency $\left(\mathrm{EC}_{50}\right.$ values of $3 \cdot 6 \pm 0 \cdot 39$ and $3 \pm 1 \mu \mathrm{M}$, respectively), but the reference drug exhibited higher selectivity (data not shown).

Mathematic parameters of drug likeness including, absorption, distribution, metabolism, excretion and toxicity properties were calculated using the pkCSM approach that uses graph-based signatures to develop predictive of ADMET (Pires et al. 2015). In silico ADMET analysis demonstrated probability of human intestinal adsorption (>90\%), while mutagenicity and inhibition of hERG1 were not predicted, besides giving acceptable predicted volumes of distribution (Tables 3 and 4).

\section{DISCUSSION}

In the last 40 years the only available treatment for $\mathrm{CD}$ has been two nitrohetocyclic agents, $\mathrm{Bz}$ and

Table 1. In vitro activity of the amidines and benznidazole on bloodstream trypomastigotes of the $\mathrm{Y}$ strain and on cardiac cells : $\mathrm{EC}_{50}$ and $\mathrm{EC}_{90}$ values after 2 and $24 \mathrm{~h}, \mathrm{CC}_{50}$ values of $\mathrm{CC}$ after $24 \mathrm{~h}$ of incubation at $37^{\circ} \mathrm{C}$, respectively, and the corresponding selectivity index (SI)

\begin{tabular}{|c|c|c|c|c|c|c|}
\hline \multirow[b]{2}{*}{ Compound } & \multicolumn{2}{|c|}{$\mathrm{EC}_{50}($ mean \pm s.D. $) \mu \mathrm{M}$} & \multicolumn{2}{|c|}{$\mathrm{EC}_{90}($ mean \pm s.D. $) \mu \mathrm{M}$} & \multicolumn{2}{|c|}{$\mathrm{CC}_{50}($ mean \pm s.D. $) \mu \mathrm{M}$} \\
\hline & $2 \mathrm{~h}$ & $24 \mathrm{~h}$ & $2 \mathrm{~h}$ & $24 \mathrm{~h}$ & $24 \mathrm{~h}$ & SI $24 \mathrm{~h}^{\mathrm{a}}$ \\
\hline $\mathrm{Bz}$ & $>32$ & $9 \cdot 6 \pm 1 \cdot 4$ & $>32$ & $30 \cdot 6 \pm 0 \cdot 64$ & $>1000$ & $>104$ \\
\hline DB2228 & $9 \cdot 3 \pm 0 \cdot 75$ & $8 \cdot 3 \pm 3 \cdot 2$ & $>32$ & $25 \cdot 9 \pm 4 \cdot 2$ & $>96$ & $>12$ \\
\hline DB2229 & $6 \cdot 3 \pm 3 \cdot 7$ & $2 \cdot 7 \pm 0 \cdot 3$ & $9 \cdot 8 \pm 1 \cdot 3$ & $8 \cdot 1 \pm 1 \cdot 37$ & $>96$ & $>36$ \\
\hline DB2292 & $7 \cdot 2 \pm 1$ & $3 \cdot 1 \pm 0 \cdot 9^{\mathrm{b}}$ & $24 \cdot 4 \pm 1 \cdot 5$ & $10 \cdot 8 \pm 2 \cdot 9$ & $>96$ & $>31$ \\
\hline DB2294 & $5 \cdot 2 \pm 2 \cdot 9$ & $3 \cdot 9 \pm 1 \cdot 3^{b}$ & $9 \cdot 6 \pm 1 \cdot 7$ & $9 \pm 0 \cdot 5$ & $>96$ & $>25$ \\
\hline DB2232 & $19 \cdot 6 \pm 0 \cdot 3$ & $7 \cdot 4 \pm 0 \cdot 6$ & $>32$ & $30 \cdot 6 \pm 1 \cdot 1$ & $>96$ & $>13$ \\
\hline DB2235 & $>32$ & $5 \cdot 27 \pm 3 \cdot 7$ & $>32$ & $10 \cdot 3 \pm 0 \cdot 35$ & $49 \pm 21$ & 9 \\
\hline DB2251 & $>32$ & $10 \cdot 1 \pm 2 \cdot 5$ & $>32$ & $28 \cdot 9 \pm 1 \cdot 8$ & $62 \pm 23$ & 6 \\
\hline DB2253 & $>32$ & $19 \pm 8$ & $>32$ & $>32$ & $>96$ & $>5$ \\
\hline DB2255 & $5 \cdot 5 \pm 2 \cdot 25$ & $3 \cdot 6 \pm 2 \cdot 4^{\mathrm{b}}$ & $>32$ & $6 \cdot 46 \pm 3 \cdot 2$ & $>96$ & $>27$ \\
\hline
\end{tabular}

a Based on $\mathrm{EC}_{50} 24 \mathrm{~h}$.

b Student's $t$-test statistical analysis of studied compound and Bz: $(P<0 \cdot 05)$. 
Table 2. Activity of the amidines and benznidazole on L929 cell lines infected with Trypanosoma cruzi (Tulahuen strain transfected with $\beta$-galactosidase) after $96 \mathrm{~h}$ of incubation with $10 \mu \mathrm{M}$ of each compound

\begin{tabular}{lll}
\hline \hline & $\begin{array}{l}\text { \% of parasite } \\
\text { growth inhibition }\end{array}$ & CC $_{50}$ \\
\hline Bz & $83 \pm 5$ & $>100$ \\
DB2228 & $46 \pm 18$ & $>96$ \\
DB2229 & $50 \pm 10$ & $>96$ \\
DB2292 & $39 \pm 22$ & $>96$ \\
DB2294 & $7 \pm 5$ & $>96$ \\
DB2232 & $22 \pm 10$ & $>96$ \\
DB2235 & $58 \pm 14$ & $>96$ \\
DB2251 & $70 \pm 17$ & $>96$ \\
DB2253 & $70 \pm 17$ & $>96$ \\
DB2255 & $88 \pm 11$ & $>96$ \\
\hline \hline
\end{tabular}

Nif, despite their severe side effects and low efficiency during the later chronic phase (Wilkinson and Kelly, 2009; Don and Ioset, 2013). The limitations of these therapies highlight the urgent need to find more effective and safer new compounds. Many compounds have been developed and screened with different experimental models of neglected diseases including CD (Bilbe, 2015). The azole anti-fungal inhibitors posaconazole ( $\mathrm{Pos}$ ) and ravuconazole (Rav) that act on the sterol $14 \alpha-$ demethylase (CYP51) enzyme although were very potent in vitro and in vivo (using dog and mouse models) (Urbina et al. 1998; Diniz et al. 2010; Keenan and Chaplin, 2015) unfortunately failed during clinical trials performed by the Drugs for Neglected Diseases initiative (Molina et al. 2014). In addition, another recent clinical trial called 'Benznidazole Evaluation for Interrupting Trypanosomiasis' (BENEFIT) designed to evaluate the efficacy and safety of $\mathrm{Bz}$ compared with placebo, did not demonstrate protection by this drug against clinical outcomes among patients with chronic CD. Often, in drug development for CD, as well as for other pathologies, there is a lack of direct translation between pre-clinical in vitro and in vivo results and clinical outcomes. Experimental chemotherapy for CD presents serious challenges in part due to experimental difficulties related to reliable demonstration of a sterile cure, particularly during the chronic stage of infection when parasite burden is low and tissue distribution is not fully understood (Chatelain and Konar, 2015; Francisco et al. 2015).

Our group has studied the in vitro and in vivo activity of AA and analogues and the bulk of the data revealed very promising action of these cations against intracellular pathogens, including T. cruzi (Soeiro et al. 2013). Presently, nine aromatic compounds were evaluated by phenotypic and in silico studies. The mono-amidines (DB2228, DB2229, DB2292 and DB2294) with tethered aryl rings chosen due to previous observation that this class display potent effect against this parasite (SimõesSilva et al. 2016). Three of the four diamidines (DB2235, DB2251 and DB2253) are analogues of furamidine and one (DB2232) is an extended bisamidino benzimidazole, which represents another class of highly active diamidines. Lastly, one novel bis-AIA (DB2255) results from a simple modification of the structure of the highly active anti- $T$. cruzi compound DB766 (Batista et al. 2010). In DB2255, the central furan ring of DB766 replaced with a non-aromatic 5-membered imidazolidin-2one ring.

Results of calculations using the pkCSM approach for estimation of ADMET and other drug-like properties are important to consider at an early stage in the drug discovery process (Pires et al. 2015). The in silico estimation of ADMET properties showed that only DB2229, DB2235, DB2251 and DB2253 are likely to permeate $\mathrm{Caco} 2$ cells, with values near of the adopted threshold of 0.9 . In addition, DB2228, DB2229, DB2251, DB2253, DB2255, DB2292 and DB2294 are predicted to show good adsorption (above $90 \%$ ) by human intestines and reasonable predicted volume of distribution. Regarding the toxicity predictors, none expected to be mutagenic nor inhibitors of hERGI, whereas all compounds are expected to inhibit hERGII and have hepatotoxic profile as has also the reference drug, Bz.

Regarding the biological phenotypic assays, seven of out nine amidines presently screened against bloodstream forms resulted in parasite death rates similar to $\mathrm{Bz}$ including mono-amidines DB2228, DB2229, DB2292, DB2294, diamidines DB2232, DB2235 and AIA DB2255. Another important characteristic of some (DB2228, DB2229, DB2235, DB2292 and DB2294) was the ability to fast kill the parasite exhibiting anti-trypomastigote activity after $2 \mathrm{~h}$ of exposure while $\mathrm{Bz}$ was completely inactive at this time of drug exposure. When these aromatic compounds were tested against the intracellular amastigotes the bis-AIA DB2255 that was one of the best molecules against B'T forms, also presented anti-parasitic effect in the same range as $\mathrm{Bz}$, even using a different parasite strain and DTUs (Y and Tulahuen for BT and intracellular forms, corresponding to DTU II and VI, respectively). These data corroborate our previous findings that demonstrated the promising trypanocidal phenotypic effect of bis-AIAs (De Araujo et al. 2014; Timm et al. 2014). Data using trypomastigotes collected from infected cell lines reported $\mathrm{EC}_{50}$ values of $2 \cdot 8$ and $15 \cdot 2 \mu \mathrm{M}$ for pentamidine exposure using $\mathrm{Y}$ and Dm28c strains, respectively (Díaz et al. 2014). However, DB2255 was less potent than other studied AIAs such as DB766 which gives $\mathrm{EC}_{50}$ values at $<0 \cdot 1 \mu \mathrm{M}$ (Batista et al. 2010). This result demonstrates that to achieve high anti-T. cruzi activity using the DB766 scaffold a central five membered 


\begin{tabular}{|c|c|c|c|c|c|c|c|c|c|c|}
\hline & DB2228 & DB2229 & DB2232 & DB2235 & DB2251 & DB2253 & DB2255 & DB2292 & DB2294 & $\mathrm{Bz}$ \\
\hline \multicolumn{11}{|l|}{ Absorption } \\
\hline $\mathrm{CaCo}_{2}$ permeability $\left(\log \mathrm{cm} \mathrm{s}^{-1}\right)$ & $0 \cdot 316$ & $0 \cdot 858$ & $0 \cdot 086$ & $0 \cdot 824$ & $1 \cdot 124$ & $0 \cdot 998$ & $0 \cdot 026$ & $0 \cdot 163$ & $0 \cdot 199$ & $0 \cdot 479$ \\
\hline Intestinal absorption (human, \%) & $97 \cdot 185$ & 100 & $86 \cdot 259$ & $82 \cdot 685$ & $94 \cdot 223$ & $93 \cdot 881$ & $90 \cdot 08$ & $96 \cdot 671$ & $93 \cdot 916$ & $68 \cdot 885$ \\
\hline Skin permeability $(\log K p)$ & $-2 \cdot 741$ & $-3 \cdot 011$ & $-2 \cdot 947$ & $-3 \cdot 713$ & $-3 \cdot 51$ & $-3 \cdot 629$ & $-2 \cdot 838$ & $-2 \cdot 818$ & $-2 \cdot 759$ & $-2 \cdot 893$ \\
\hline \multicolumn{11}{|l|}{ Distribution } \\
\hline VDss (human) (log VDss $\left.\left(\mathrm{L} \mathrm{kg}^{-1}\right)\right)$ & $0 \cdot 645$ & $0 \cdot 709$ & $0 \cdot 318$ & $0 \cdot 482$ & 0.93 & $0 \cdot 705$ & $0 \cdot 449$ & $0 \cdot 573$ & $0 \cdot 521$ & $-0 \cdot 104$ \\
\hline Fraction unbound (human) & $0 \cdot 307$ & $0 \cdot 2$ & $0 \cdot 278$ & $0 \cdot 35$ & $0 \cdot 278$ & $0 \cdot 316$ & $0 \cdot 187$ & $0 \cdot 213$ & $0 \cdot 221$ & $0 \cdot 503$ \\
\hline BBB permeability & $-1 \cdot 185$ & $-0 \cdot 85$ & $-1 \cdot 086$ & $-0 \cdot 157$ & $0 \cdot 13$ & $0 \cdot 007$ & $-1 \cdot 265$ & $-1 \cdot 249$ & $-1 \cdot 465$ & $-0 \cdot 619$ \\
\hline CNS permeability & $-1 \cdot 913$ & $-2 \cdot 298$ & $-2 \cdot 944$ & $-2 \cdot 439$ & $-2 \cdot 095$ & $-2 \cdot 151$ & $-2 \cdot 526$ & $-2 \cdot 766$ & $-3 \cdot 072$ & $-2 \cdot 995$ \\
\hline \multicolumn{11}{|l|}{ Metabolism } \\
\hline CYP2D6 substrate & No & No & No & No & No & No & No & No & No & No \\
\hline CYP3A4 substrate & Yes & Yes & Yes & Yes & Yes & Yes & Yes & Yes & Yes & No \\
\hline CYP1A2 inhibitor & No & No & No & No & No & No & No & No & No & No \\
\hline CYP2C19 inhibitor & No & No & No & No & No & No & No & No & No & No \\
\hline CYP2C9 inhibitor & No & No & No & No & No & No & No & No & No & No \\
\hline CYP2D6 inhibitor & No & No & No & No & No & No & No & No & No & No \\
\hline CYP3A4 inhibitor & Yes & Yes & Yes & No & Yes & No & Yes & Yes & Yes & No \\
\hline \multicolumn{11}{|l|}{ Excretion } \\
\hline Total clearance $\log \left(\mathrm{ml} \mathrm{min}{ }^{-1} \mathrm{~kg}^{-1}\right)$ & $1 \cdot 117$ & $1 \cdot 322$ & $1 \cdot 74$ & $1 \cdot 177$ & $0 \cdot 598$ & $0 \cdot 628$ & $0 \cdot 605$ & $1 \cdot 459$ & $1 \cdot 649$ & $0 \cdot 625$ \\
\hline
\end{tabular}

Table 4. In silico toxicity

\begin{tabular}{|c|c|c|c|c|c|c|c|c|c|c|}
\hline & DB2228 & DB2229 & DB2232 & DB2235 & DB2251 & DB2253 & DB2255 & DB2292 & DB2294 & $\mathrm{Bz}$ \\
\hline AMES toxicity & No & No & No & No & No & No & No & No & No & Yes \\
\hline Max. tolerated dose (human) (log $\mathrm{mg} \mathrm{kg}^{-1} \mathrm{day}^{-1}$ ) & $0 \cdot 346$ & $-0 \cdot 896$ & $-0 \cdot 719$ & $-0 \cdot 109$ & $-0 \cdot 494$ & $-0 \cdot 233$ & $-0 \cdot 624$ & $-0 \cdot 838$ & $-0 \cdot 741$ & $0 \cdot 984$ \\
\hline hERG I inhibitor & No & No & No & No & No & No & No & No & No & No \\
\hline hERG II inhibitor & Yes & Yes & Yes & Yes & Yes & Yes & Yes & Yes & Yes & No \\
\hline Oral rat acute toxicity $(\mathrm{lD} 50)\left(\mathrm{mol} \mathrm{kg}^{-1}\right)$ & $2 \cdot 776$ & $3 \cdot 007$ & $2 \cdot 577$ & $2 \cdot 451$ & $2 \cdot 887$ & $2 \cdot 785$ & $2 \cdot 841$ & $2 \cdot 758$ & $2 \cdot 53$ & $2 \cdot 454$ \\
\hline Oral rat chronic toxicity (LOAEL) $\log \left(\mathrm{mg} \mathrm{kg}^{-1} \mathrm{~b}_{\mathrm{bw}} \mathrm{day}^{-1}\right)$ & $2 \cdot 577$ & $0 \cdot 511$ & $0 \cdot 981$ & $1 \cdot 483$ & $1 \cdot 085$ & $1 \cdot 213$ & $0 \cdot 407$ & $0 \cdot 471$ & $0 \cdot 436$ & $1 \cdot 649$ \\
\hline Hepatotoxicity & Yes & Yes & Yes & Yes & Yes & Yes & Yes & Yes & Yes & Yes \\
\hline Skin sensitisation & No & No & No & No & No & No & No & No & No & No \\
\hline T. Pyriformis toxicity pIGC50 $\left(\log\right.$ ug $\left.\mathrm{L}^{-1}\right)$ & $0 \cdot 285$ & $0 \cdot 3$ & $0 \cdot 308$ & $0 \cdot 946$ & $0 \cdot 475$ & $0 \cdot 807$ & $0 \cdot 329$ & $0 \cdot 29$ & $0 \cdot 287$ & $1 \cdot 227$ \\
\hline Minnow toxicity $\log$ LC50 $(\mathrm{mM})$ & $0 \cdot 276$ & $0 \cdot 125$ & $0 \cdot 822$ & $1 \cdot 156$ & $0 \cdot 726$ & 0.925 & $-0 \cdot 069$ & $-0 \cdot 025$ & $-0 \cdot 19$ & $1 \cdot 649$ \\
\hline
\end{tabular}


hetero aromatic ring is required. In addition, is important to take into consideration that a hit compound for CD must be active against both parasite stages and upon the different DTUs in order to be given in the distinct endemic areas of this neglected disease (Chatelain, 2015).

\section{ACKNOWLEDGEMENTS}

The authors acknowledge the Program for Technological Development in Tools for Health-PDTIS-FIOCRUZ for use of its facilities.

\section{FINANCIAL SUPPORT}

The present study was supported by grants from Fundação Carlos Chagas Filho de Amparo a Pesquisa do Estado do Rio de Janeiro (FAPERJ), Conselho Nacional de Desenvolvimento Científico e Tecnológico (CNPq) and Fundação Oswaldo Cruz, Instituto Oswaldo Cruz, PROEP/CNPq/Fiocruz. M.N.C.S. is a research fellow of $\mathrm{CNPq}$ and $\mathrm{CNE}$ research. This work was also supported, in part, by the National Institutes of Health USA Grant No. RO1AI64200 and by The Bill and Melinda Gates Foundation through a subcontract with the CPDD (to D.W.B.).

\section{CONFLICT OF INTEREST}

None.

\section{REFERENCES}

Albajar-Viñas, P. and Dias, J. C. (2014). Advancing the treatment for Chagas' disease. New England Fournal of Medicine 15, 1942-1943.

Batista, D. G., Batista, M. M., de Oliveira, G. M., do Amaral, P. B., Lannes-Vieira, J., Britto, C. C., Junqueira, A., Lima, M. M., Romanha, A. J., Sales Junior, P. A., Stephens, C. E., Boykin, D. W. and Soeiro, M. N. (2010). Arylimidamide DB766, a potential chemotherapeutic candidate for Chagas' disease treatment. 2010. Antimicrobial Agents and Chemotherapy 54, 2940-2952.

Bilbe, G. (2015). Infectious diseases. Overcoming neglect of kinetoplastid diseases. Science 29, 974-976.

Buckner, F. S., Verlinde, C. L. M. J., La Flamme, A. C. and van Voorhis, W. C. (1996). Efficient technique for screening drugs activity against Trypanosoma cruzi using parasites expressing $\beta$-galactosidase. Antimicrobial Agents and Chemotherapy 40, 2592-2597.

Chatelain, E. (2015). Chagas disease drug discovery: toward a new era. Fournal of Biomolecular Screening 20, 22-35.

Chatelain, E. and Konar, N. (2015). Translational challenges of animal models in Chagas disease drug development: a review. Fournal of Drug Design Development and Therapy 19, 4807-4823.

Coura, J. R. and Dias, J. C. (2015). Epidemiology, control and surveillance of Chagas disease: 100 years after its discovery. Memórias do Instituto Oswaldo Cruz 104(Suppl.), 31-40.

De Araújo, J. S., Da Silva, C. F., Batista, D. G., Da Silva, P. B., Meuser, M. B., Aiub, C. A., da Silva, M. F., Araújo-Lima, C. F., Banerjee, M., Farahat, A. A., Stephens, C. E., Kumar, A., Boykin, D. W. and Soeiro, M. N. (2014). In vitro and in vivo studies of the biological activity of novel arylimidamides against Trypanosoma cruzi. Antimicrobial Agents and Chemotherapy 58, 4191-4195.

De Souza, E. M., Lansiaux, A., Bailly, C., Wilson, W. D., Hu, Q., Boykin, D. W., Batista, M. M., Araújo-Jorge, T. C. and Soeiro, M. N. (2004). Phenyl substitution of furamidine markedly potentiates its anti-parasitic activity against Trypanosoma cruzi and Leishmania amazonensis. Biochemical Pharmacology Fournal 15, 593-600.

Díaz, M. V., Miranda, M. R., Campos-Estrada, C., Reigada, C., Maya, J. D., Pereira, C. A. and López-Muñoz, R. (2014) Pentamidine exerts in vitro and in vivo anti Trypanosoma cruzi activity and inhibits the polyamine transport in Trypanosoma cruzi. Acta Tropica fournal 134, 1-9.
Diniz, L. de F., Caldas, I. S., Guedes, P. M., Crepalde, G., de Lana, M., Carneiro, C. M., Talvani, A., Urbina, J. A. and Bahia, M. T. (2010). Effects of ravuconazole treatment on parasite in dogs experimentally Infected with Trypanosoma cruzi. Antimicrobial Agents and Chemotherapy 54, 2979-2986.

Don, R. and Ioset, J. R. (2013). Screening strategies to identify new chemical diversity for drug development to treat kinetoplastid infections. Parasitology 141, 140-146.

Drugs for Neglected Diseases Initiave (2016). Chagas Disease Target Product Profile. http://www.dndi.org/diseases-projects/portfolio.html (accessed June 4, 2016).

Farahat, A. A., Paliakov, E., Kumar, A., Barghash, A. E., Goda, F. E., Eisa, H. M., Wenzler, T., Brun, R., Liu, Y., Wilson, W. D. and Boykin, D. W. (2011). Exploration of larger central ring linkers in furamidine analogues: synthesis and evaluation of their DNA binding, antiparasitic and fluorescence properties. Bioorganic and Medicinal Chemistry 1, 2156-2167.

Francisco, A. F., Lewis, M. D., Jayawardhana, S., Taylor, M. C., Chatelain, E. and Kelly, J. M. (2015). Limited ability of posaconazole to cure both acute and chronic Trypanosoma cruzi infections revealed by highly sensitive in vivo imaging. Antimicrobial Agents and Chemotherapy 59, 4653-4661

Green, J. (2014). Synthesis of aza-heterocyclic monoamidines as potential DNA minor groove binders, anti-trypanosomals, and boron neutron capture therapy agents. Dissertation, Georgia State University. http:// scholarworks.gsu.edu/chemistry_diss/101.

Ismail, M. A., Brun, R., Wenzler, T., Tanious, F. A., Wilson, W. D. and Boykin, D. W. (2004). Dicationic biphenyl benzimidazole derivatives as antiprotozoal agents. Bioorganic and Medicinal Chemistry 15, 5405-5413.

Keenan, M. and Chaplin, J. H. (2015). A new era for chagas disease drug discovery? Progress in Medicinal Chemistry 54, 185-230.

King, H., Lourie, E. M. and Yorke, W. (1937). New trypanocidal substances. Lancet 230, 1360-1136.

Marin-Neto, J. A., Rassi, A., Jr., Morillo, C. A., Avezum, A., Connolly, S. J., Sosa-Estani, S., Rosas, F., Yusuf, S. and Benefit, I. (2008). Rationale and design of a randomized placebo-controlled trial assessing the effects of etiologic treatment in Chagas' cardiomyopathy: the benznidazole evaluation for interrupting trypanosomiasis (BENEFIT). American Heart Yournal 156, 37-43.

Meirelles, M. N., de Araujo-Jorge, T. C., Miranda, C. F., de Souza, W. and Barbosa, H. S. (1986). Interaction of Trypanosoma cruzi with heart muscle cells: ultrastructural and cytochemical analysis of endocytic vacuole formation and effect upon myogenesis in vitro. European Fournal of Cell Biology 41, 198-206.

Molina, I., Gómez, i Prat.J., Salvador, F., Treviño, B., Sulleiro, E., Serre, N., Pou, D., Roure, S., Cabezos, J., Valerio, L., BlancoGrau, A., Sánchez-Montalvá, A., Vidal, X. and Pahissa, A. (2014) Randomized trial of posaconazole and benznidazole for chronic Chagas' disease. New England Yournal of Medicine 15, 1899-1908.

Morillo, C. A., Marin-Neto, J. A., Avezum, A., Sosa-Estani, S., Rassi, A., Jr., Rosas, F., Villena, E., Quiroz, R., Bonilla, R., Britto, C., Guhl, F., Velazquez, E., Bonilla, L., Meeks, B., RaoMelacini, P., Pogue, J., Mattos, A., Lazdins, J., Rassi, A., Connolly, S. J., Yusuf, S. and BENEFIT, I. (2015). Randomized trial of benznidazole for chronic Chagas' cardiomyopathy. New England Yournal of Medicine 373, 1295-1306.

Patterson, S. and Wyllie, S. (2014). Nitro drugs for the treatment of trypanosomatid diseases: past, present, and future prospects. Trends in Parasitology 30, 289-298.

Pires, D. E., Blundell, T. L. and Ascher, D. B. (2015). pkCSM: predicting small-molecule pharmacokinetic and toxicity properties using graphbased signatures. Fournal of Medicine Chemistry 14, 4066-4072.

Romanha, A. J., Castro, S. L., Soeiro, M. N., Lannes-Vieira, J., Ribeiro, I., Talvani, A., Bourdin, B., Blum, B., Olivieri, B., Zani, C., Spadafora, C., Chiari, E., Chatelain, E., Chaves, G., Calzada, J. E., Bustamante, J. M., Freitas-Junior, L. H., Romero, L. I., Bahia, M. T., Lotrowska, M., Soares, M., Andrade, S. G., Armstrong, T., Degrave, W. and Andrade, Z. A. (2010). In vitro and in vivo experimental models for drug screening and development for Chagas disease. Memórias do Instituto Oswaldo Cruz 105, 233-238.

Simões-Silva, M. R., Nefertiti, A. S. G., De Araújo, J. S., Batista, M. M., Da Silva, P. B., Bahia, M. T., Menna-Barreto, R. S., Pavão, B. P., Green, J., Farahat, A. A., Kumar, A., Boykin, D. W. and Soeiro, M. N. C. (2016). Phenotypic screening in vitro of novel aromatic amidines against Trypanosoma cruzi. Antimicrobial Agents and Chemotherapy 60, 4701-4707.

Soeiro, M. N., de Castro, S. L., de Souza, E. M., Batista, D. G., Silva, C. F. and Boykin, D. W. (2008). Diamidine activity against 
trypanosomes: the state of the art. Current Molecular Pharmacology 1, 151-161.

Soeiro, M. N., Werbovetz, K., Boykin, D. W., Wilson, W. D. Wang, M. Z. and Hemphill, A. (2013). Novel amidines and analogues as promising agents against intracellular parasites: a systematic review. Parasitology 140, 929-951.

Stephens, C. E., Tanious, F., Kim, S., Wilson, W. D., Schell, W. A., Perfect, J. R., Franzblau, S. G. and Boykin, D. W. (2001) Diguanidino and "reversed" diamidino 2,5-diarylfurans as antimicrobial agents. Fournal of Medicinal Chemistry 24, 1741-1748.

Teixeira, A. R., Nascimento, R. J. and Sturm, N. R. (2006). Evolution and pathology in chagas disease-a review. Memórias do Instituto Oswaldo Cruz 101, 463-491.

Timm, B. L., da Silva, P. B., Batista, M. M., da Silva, F. H., da Silva, C. F., Tidwell, R. R., Patrick, D. A., Jones, S. K., Bakunov, S. A., Bakunova, S. M. and Soeiro, M. N. (2014). In vitro and in vivo biological effects of novel arylimidamide derivatives against Trypanosoma cruzi. Antimicrobial Agents and Chemotherapy 58, 37203726.

Urbina, J. A., Payares, G., Contreras, L. M., Liendo, A., Sanoja, C., Molina, J., Piras, M., Piras, R., Perez, N., Wincker, P. and
Loebenberg, D. (1998). Antiproliferative effects and mechanism of action of SCH 56592 against Trypanosoma (Schizotrypanum) cruzi: in vitro and in vivo studies. Antimicrobial Agents and Chemotherapy 42, 1771-1777

Wilkinson, S. R. and Kelly, J. M. (2009). Trypanocidal drugs: mechanisms, resistance and new targets. Expert Reviews in Molecular Medicine Fournal 11, 1-25.

Wilkinson, S. R., Taylor, M. C., Horn, D., Kelly, J. M. and Cheeseman, I. A. (2008). A mechanism for cross-resistance to nifurtimox and benznidazole in trypanosomes. Proceedings of the National Academy of Sciences of the United States of America 105, 5022-5027.

World Health Organization (2016). What is Chagas Disease? (WHO) Third WHO Report on Neglected Tropical Diseases. Department of Control of Neglected Tropical Diseases, World Health Organization, Geneva.

Zingales, B., Andrade, S. G., Briones, M. R., Campbell, D. A., Chiari, E., Fernandes, O., Guhl, F., Lages-Silva, E., Macedo, A. M. Machado, C. R., Miles, M. A., Romanha, A. J., Sturm, N. R., Tibayrenc, M., Schijman, A. G. and Second Satellite Meeting (2009). A new consensus for Trypanosoma cruzi intraspecific nomenclature: second revision meeting recommends TcI to TcVI. Memórias do Instituto Oswaldo Cruz 104, 1051-1054. 